\title{
Systolic blood pressure relates to the rate of progression of albuminuria in NIDDM
}

\author{
A.Schmitz ${ }^{1}$, M. Vath ${ }^{2}$, C.E.Mogensen ${ }^{1}$ \\ ${ }^{1}$ Medical Department M, Diabetes and Endocrinology, Aarhus Kommunehospital, Aarhus, Denmark \\ ${ }^{2}$ Department of Theoretical Statistics, University of Aarhus, Aarhus, Denmark
}

Summary We prospectively followed a cohort of 278 non-insulin-dependent (NIDDM) patients for a 6year period, intending to estimate the rate of increase of albuminuria and to identify clinical variables that influence this increase. At baseline, normoalbuminuria $(\mathrm{N})$ was seen in $74 \%$, microalbuminuria (M) in $19 \%$ and $7 \%$ presented with proteinuria $(\mathrm{P})$. A total of 80 patients died; they were older $(p<0.001)$ and had higher albumin excretion both at baseline and as an average during follow-up $(p<0.01)$. At baseline, patients with proteinuria had higher blood pressures (systolic and diastolic), whereas there was no difference between patients with normo- and microalbuminuria. Glycaemic control was increasingly poor throughout the three groups. At follow-up, an average relative rate of increase of albuminuria (slope) of $17 \%$ per year was seen both for patients with complete 6 years, follow-up $(n=135)$ and patients with at least 4 years follow-up $(n=178)$. Slope correlated significantly with systolic blood pressure ( $r=0.26$ and 0.29$)$ in both groups, diastolic blood pressure only in the 4-year group $(r=0.22)$ and average albuminuria in both $(r=0.31$ and 0.24). By multiple regression analyses systolic blood pressure and average albuminuria remained with significant influence on slope. Progression was defined as an increase in the category (e.g. normoto microalbuminuria) as well as an increase of more than $20 \%$ in albumin excretion, and was seen in 46 patients with at least 4 years' follow-up. Progressors (patients demonstrating progression) had higher systolic blood pressure ( $165 \mathrm{~mm} \mathrm{Hg} \pm 20$ vs $156 \pm 17)$ and poorer glycaemic control $\left(\mathrm{HbA}_{1 \mathrm{c}}: 8.2 \% \pm 1.5 \mathrm{vs}\right.$ $7.7 \pm 1.3) p<0.05$, as well as a higher level of albuminuria at baseline. The present study points to systolic blood pressure and general level of albuminuria as factors determining the rate of progression of albuminuria. However, only a modest fraction of the variation between subjects was explained by these variables. [Diabetologia (1994) 37: 1251-1258]

Key words Non-insulin-dependent diabetes mellitus, albuminuria, blood pressure, rate of progression, progressors, glycaemic control.
Received: 31 March 1994

and in revised form: 20 June 1994

Corresponding author: Dr. A.Schmitz, Medical Department M (Diabetes and Endocrinology), Aarhus Kommunehospital, DK-8000 Aarhus C, Denmark

Abbreviations: IDDM, insulin-dependent diabetes mellitus; NIDDM, non-insulin-dependent diabetes mellitus; N, normal urinary albumin excretion; $M$, microalbuminuria; $P$, proteinuria; Slope, relative rate of increase; UAC, urinary albumin concentration; UAE, urinary albumin excretion rate.
The natural development of diabetic nephropathy pertaining to patients with non-insulin-dependent diabetes (NIDDM) is poorly elucidated $[1,2]$. In insulin-dependent diabetes (IDDM) approximately $30 \%$ of patients eventually develop end-stage renal failure [3], whereas in NIDDM the proportion is much lower (less than $10 \%$ ) at least in elderly Caucasian populations [4-7]. Persistent microalbuminuria (i.e. a urinary albumin excretion (UAE) from $20 \mu \mathrm{g} / \mathrm{min}$ to $200 \mu \mathrm{g} / \mathrm{min}$ ) in patients with IDDM defines the state of incipient nephropathy [3], which is the state from which approximately $80 \%$ progress to overt nephropathy over the next decade. Microalbuminuria 


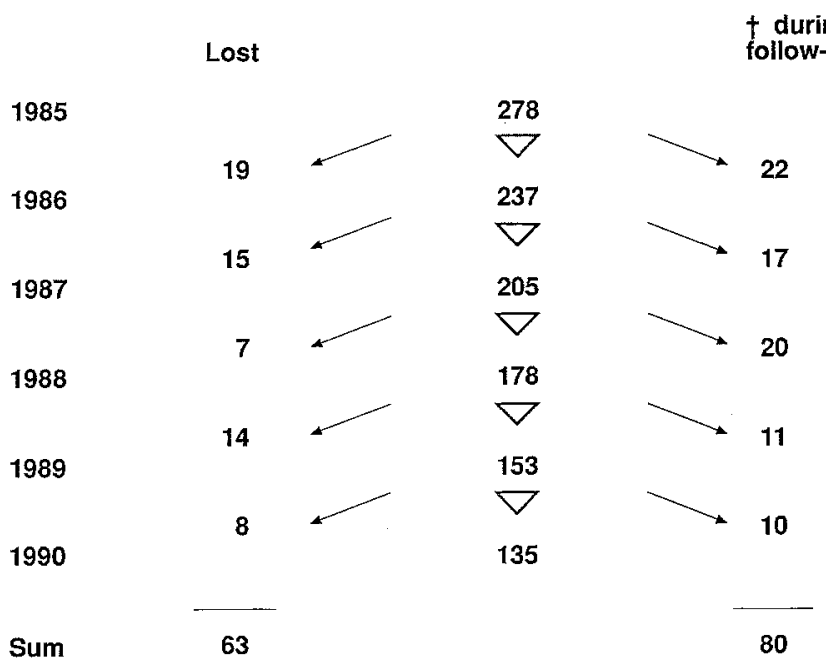

Fig. 1. Fate of the initial cohort during the 6-year observation period. Twenty-four per cent of those with normal urinary albumin excretion, $35 \%$ of normoalbuminuric and $60 \%$ of patients with proteinuria died

and proteinuria in NIDDM are frequent $(20-40 \%$ and $5-15 \%$, respectively) $[4,6-11]$, and often present at diagnosis or at early known durations $[4,11-$ 16]. Microalbuminuria in NIDDM obviously do also predict the development of clinical proteinuria [17], which will progress in some cases to renal failure, but with far less consistency than is seen in IDDM [18]. The state of incipient nephropathy has hence not been specified in NIDDM. The main enigma is that microalbuminuria in NIDDM is not as closely linked with microvascular complications [19] as it is in IDDM. The predominant implication of microalbuminuria in NIDDM is the strong independent prediction of increased mortality, which is due mainly to cardiovascular causes [6-7, 20-21].

The evolution of urinary albumin excretion in NIDDM has previously been sparsely studied, and we found it of interest to prospectively follow-up a cohort of elderly outpatients with this type of diabetes. Our aim was to estimate the rate of progression of albuminuria and the influence of potential clinical risk factors.

\section{Subjects and methods}

All Caucasian diabetic patients attending our outpatient clinic during 1985, who were born during the period 1914-1934 were followed until the end of 1990 . A total of 401 such patients were seen, 278 of whom were considered non-insulin-dependent by the following criteria: age at diagnosis 40 years or over, and treated without insulin for a period of more than 2 years.

Urinary albumin concentration (UAC) was measured by radioimmunoassay [22] in early morning urine samples at each attendance during the study period. The average UAC was calculated for each year. Mean number of measurements per person per year was 3.3 (2.9 3.7, range for years). Fasting plasma glucose was measured by standard enzymatic tech-
Table 1. Overview of subjects by number of years of follow-up and level of urinary albumin excretion at baseline

\begin{tabular}{lllcr}
\hline Years & \multicolumn{4}{l}{ Urinary albumin concentration $(\mu \mathrm{g} / \mathrm{ml})$} \\
\cline { 2 - 5 } & $\leq \mathbf{1 5}$ & $>15-\leq 200$ & $>200$ & \\
\hline 6 & 108 & 24 & 3 & 135 \\
5 & 11 & 5 & 2 & 18 \\
4 & 17 & 5 & 3 & 25 \\
3 & 21 & 5 & 1 & 27 \\
2 & 21 & 5 & 6 & 32 \\
1 & 28 & 8 & 5 & 41 \\
& 206 & 52 & 20 & 278 \\
\hline
\end{tabular}

nique, and the level of glycaemic control was described as mean during year of entrance, mean through the study period and mean of all values obtained since the diagnosis of diabetes. Haemoglobin $\mathrm{A}_{1 \mathrm{C}}\left(\mathrm{HbA}_{1 \mathrm{C}}\right)$ was measured by HPLC [23], and blood pressure after 5 min sitting was measured by a conventional sphygmomanometer with phase $\mathrm{V}$ for diastolic value. Mean values of these parameters were obtained through the study period. Antidiabetic and antihypertensive or diuretic therapy were currently recorded. Treatment modality was designated as the most "intensive" during the study period; insulin > oral hypoglycaemic agents diet.

Figure 1 delineates the fate of the initial cohort, indicating the number of patients who died or left the study. Table 1 describes the patients by number of years of follow-up and category of albuminuria at baseline (average during 1985). Normoalbuminuria defined as $\mathrm{UAC} \leq 15 \mu \mathrm{g} / \mathrm{ml}$ was seen in $74 \%$; microalbuminura $(15 \mu \mathrm{g} / \mathrm{ml}<\mathrm{UAC} \leq 200 \mu \mathrm{g} / \mathrm{ml})$ was seen in $19 \%$; and $7 \%$ presented with proteinuria (UAC $>200 \mu \mathrm{g} / \mathrm{ml}$ ).

The patients gave their informed consent and the study was performed in accordance with the Declaration of Helsinki.

\section{Statistical analysis}

For each individual the rate of progression of albuminuria was estimated from a linear regression of the annual average UAC on year of follow-up. Here and elsewhere UAC measurements were $\log _{10}$ transformed prior to any calculations and is therefore given as geometric mean $\times 1 \div$ tolerance factor. Simple (unweighted) linear regression was used, as preliminary calculations indicated that these results were essentially identical to results from a weighted linear regression using number of measurements each year as weights. The regression coefficient estimates the relative rate of increase of $U A C$, when calculated as (exp\{regression coefficient $\times \ln (10)\}-1) \times 100 \%$. This measure of progression of albuminuria is simply called "slope". $\mathrm{Pa}$ tients with few years of follow-up present with uncertain estimates of slope, due to a considerable intra-individual variation of UAC. At the same time patients with complete followup constitute a highly-selected group. To better elucidate the relative importance of these issues, all calculations were performed on three categories of subjects: those with at least 2 years of follow-up, those with at least 4 years of follow-up, and those with a complete 6-year follow-up, respectively.

The purpose of the analysis was to identify factors which could explain the interindividual variation in the slope estimates. Initially each clinical variable was assessed separately using $t$-test or one-way analysis of variance for categorical variables and correlation coefficients for quantitative variables. A multiple regression with slope as the dependent variable was finally performed in order to identify independent prognostic factors. To evaluate whether the relative rate of in- 
Table 2. Clinical data. Number or mean (range)

\begin{tabular}{|c|c|c|c|}
\hline & $\begin{array}{l}\text { Normo- } \\
\text { albuminuria }\end{array}$ & $\begin{array}{l}\text { Micro- } \\
\text { albuminuria }\end{array}$ & Proteinuria \\
\hline Sex (male/female) & $107 / 99$ & $32 / 20$ & $11 / 9$ \\
\hline Age (years) & $\begin{array}{l}63.8 \\
(51-71)\end{array}$ & $\begin{array}{l}64.7 \\
(54-71)\end{array}$ & $\begin{array}{l}63.9 \\
(51-71)\end{array}$ \\
\hline $\begin{array}{l}\text { Known diabetes } \\
\text { duration (years) }\end{array}$ & $\begin{array}{l}7.4 \\
(0-26)\end{array}$ & $\begin{array}{l}9.5^{\mathrm{b}} \\
(0-28)\end{array}$ & $\begin{array}{l}8.7 \\
(1-23)\end{array}$ \\
\hline $\begin{array}{l}\text { Body mass index } \\
\left(\mathrm{kg} / \mathrm{m}^{2}\right)\end{array}$ & $\begin{array}{l}28.2 \\
(17.6-48.3)\end{array}$ & $\begin{array}{l}28.5 \\
(16.8-55.9)\end{array}$ & $\begin{array}{l}31.5^{c} \\
(18.8-45.5)\end{array}$ \\
\hline $\begin{array}{l}\text { Plasma glucose } \\
(\mathrm{mmol} / \mathrm{l}) \mathrm{B}\end{array}$ & $\begin{array}{l}9.1 \\
(4.9-18.2)\end{array}$ & $\begin{array}{l}9.6 \\
(5.1-13.5)\end{array}$ & $\begin{array}{l}10.3 \\
(6.5-21.4)\end{array}$ \\
\hline $\begin{array}{l}\text { Plasma glucose } \\
(\mathrm{mmol} / \mathrm{l}) \mathrm{S}\end{array}$ & $\begin{array}{l}9.4 \\
(5.6-18.4)\end{array}$ & $\begin{array}{l}9.7 \\
(5.2-15.1)\end{array}$ & $\begin{array}{l}10.6^{\mathrm{b}} \\
(6.4-16.8)\end{array}$ \\
\hline $\begin{array}{l}\text { Plasma glucose } \\
(\mathrm{mmol} / \mathrm{l}) \mathrm{A}\end{array}$ & $\begin{array}{l}8.8 \\
(5.6-17.7)\end{array}$ & $\begin{array}{l}9.4^{\mathrm{b}} \\
(5.7-17.4)\end{array}$ & $\begin{array}{l}10.0^{c} \\
(5.8-14.1)\end{array}$ \\
\hline $\mathrm{HbA}_{1 \mathrm{C}}(\%)$ & $\begin{array}{l}7.7 \\
(5.3-13.1)\end{array}$ & $\begin{array}{l}8.4^{\mathrm{c}} \\
(5.4-11.8)\end{array}$ & $\begin{array}{l}8.2 \\
(7.2-9.9)\end{array}$ \\
\hline $\begin{array}{l}\text { Blood pressure } \\
\text { systolic }(\mathrm{mm} \mathrm{Hg}) \\
\text { diastolic }(\mathrm{mm} \mathrm{Hg})\end{array}$ & $\begin{array}{l}155 \\
(110-213) \\
87 \\
(65-120)\end{array}$ & $\begin{array}{l}158 \\
(110-207) \\
87 \\
(60-104)\end{array}$ & $\begin{array}{l}171^{\mathrm{a}, \mathrm{c}} \\
(141-210) \\
92^{\mathrm{a}, \mathrm{b}} \\
(70-111)\end{array}$ \\
\hline $\mathrm{UAC}(\mu \mathrm{g} / \mathrm{ml})$ & $\begin{array}{l}4.5 \\
(0.4-15)\end{array}$ & $\begin{array}{l}38.7 \\
(16-149)\end{array}$ & $\begin{array}{l}560.5 \\
(204-1603)\end{array}$ \\
\hline Treatment (D/T/I) & $35 / 145 / 26$ & $5 / 33 / 14$ & $2 / 13 / 5$ \\
\hline $\mathrm{AH}(\%)$ & 43 & 62 & 70 \\
\hline
\end{tabular}

${ }^{\mathrm{a}} p<0.05$ vs $\mathrm{M} ;{ }^{\mathrm{b}} p<0.05$ vs $\mathrm{N} ;{ }^{\mathrm{c}} p<0.01$ vs $\mathrm{N}$.

B/S/A, Baseline/study period/all; D/T/I, Diet/Tablet/Insulin; $\mathrm{AH}$, Antihypertensive/diuretic treatment

Table 3. Correlations between clinical variables and albuminuria at baseline including all subjects. Significant associations $(p<0.05)$ are indicated by bold figures

\begin{tabular}{lll}
\hline & & Baseline albuminuria \\
\hline Age & (B) & 0.070 \\
Diabetes duration & (B) & 0.108 \\
Body mass index & (S) & $\mathbf{0 . 1 8 3}$ \\
Plasma glucose & (B) & $\mathbf{0 . 1 3 1}$ \\
& (S) & $\mathbf{0 . 1 3 4}$ \\
HbA $_{1 C}$ & (A) & $\mathbf{0 . 1 9 7}$ \\
Blood pressure & (S) & $\mathbf{0 . 1 7 2}$ \\
$\quad$ systolic & (S) & $\mathbf{0 . 1 6 8}$ \\
diastolic & (S) & $\mathbf{0 . 1 5 1}$ \\
\hline
\end{tabular}

crease was associated with the level of albuminuria, the average UAC during follow-up was computed for each individual and used as an independent variable in the analyses. Unlike baseline UAC the average will not give rise to a "regression towards the mean" phenomenon.

It is well known that among diabetic patients some develop vascular complications, whereas others do not. The present group of patients may therefore be viewed as a mixture of two "subpopulations", and we performed additional analyses from this perspective. "Progressors" were defined as those patients who exhibited an increase in the category of albumin excretion (e.g. normo- $\rightarrow$ microalbuminuria) as well as an increase of more than $20 \%$ from baseline. The two groups, progressors

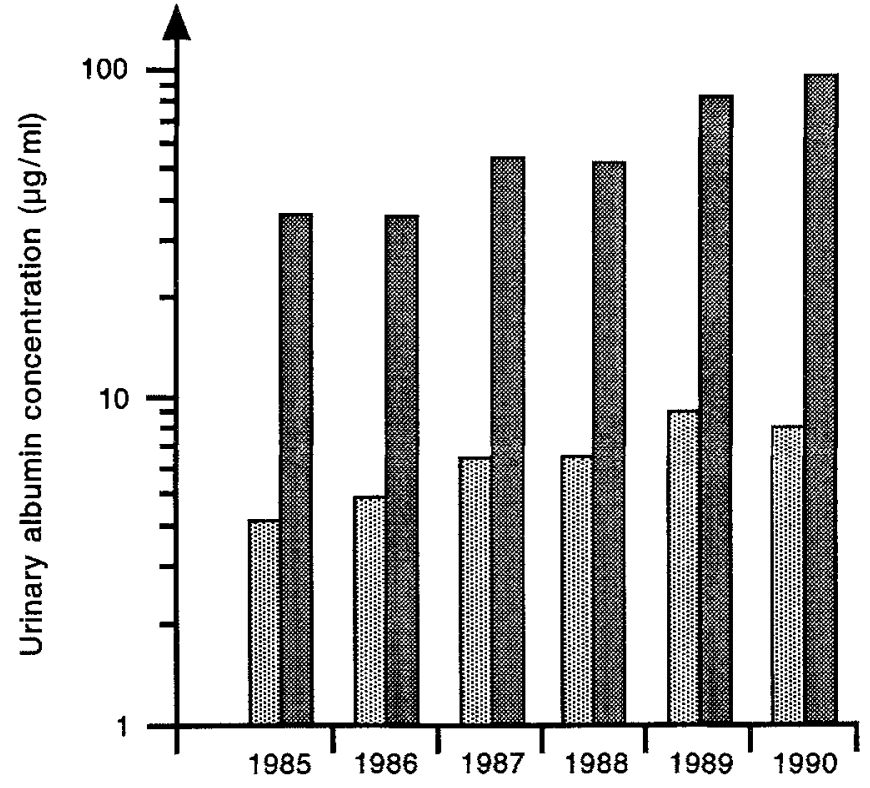

Annual albumin excretion

Fig. 2. Average annual albumin excretion in 108 patients with normal urinary albumin excretion and 24 with microalbuminuria at baseline, who completed the 6-year followup

and non-progressors, were then compared with respect to the distribution of the clinical variables.

\section{Results}

Clinical characteristics of the patients appear in Table 2. Patients with proteinuria exhibited both higher systolic as well as diastolic blood pressure, but blood pressure was similar in patients with normal urinary albumin excretion and microalbuminuria. Glycaemic control was increasingly poor throughout the three groups, as evaluated by plasma glucose values. $\mathrm{HbA}_{1 \mathrm{C}}$ was similarly elevated in microalbuminuric and proteinuric patients. Insulin was required in $13 \%, 27 \%$ and $25 \%$, respectively. Correlations between clinical parameters and urinary albumin excretion at baseline including all subjects appear in Table 3, and associations with albuminuria at baseline and average for patients with complete 6-years follow-up are presented in Table 4. Average albuminuria was significantly associated with glycaemic control and systolic blood pressure.

The average annual albumin excretion for patients who completed the 6-year follow-up are shown in Figure 2. Those with normal UAC rose from $4.2 \mu \mathrm{g} /$ $\mathrm{ml} \times 1 \div 1.9$ to $8.3 \times 1 \div 2.8, p<0.0001$, and microalbuminuria increased from $36.4 \mu \mathrm{g} / \mathrm{ml} \times / \div 1.9$ to $96.9 \times 1 \div 4.0, p<0.01$. The individual courses of the microalbuminuric patients are given in Figure 3, which also demonstrates the intraindividual variation. The relative rate of increase in urinary albumin excretion was estimated for patients with values for 
1254

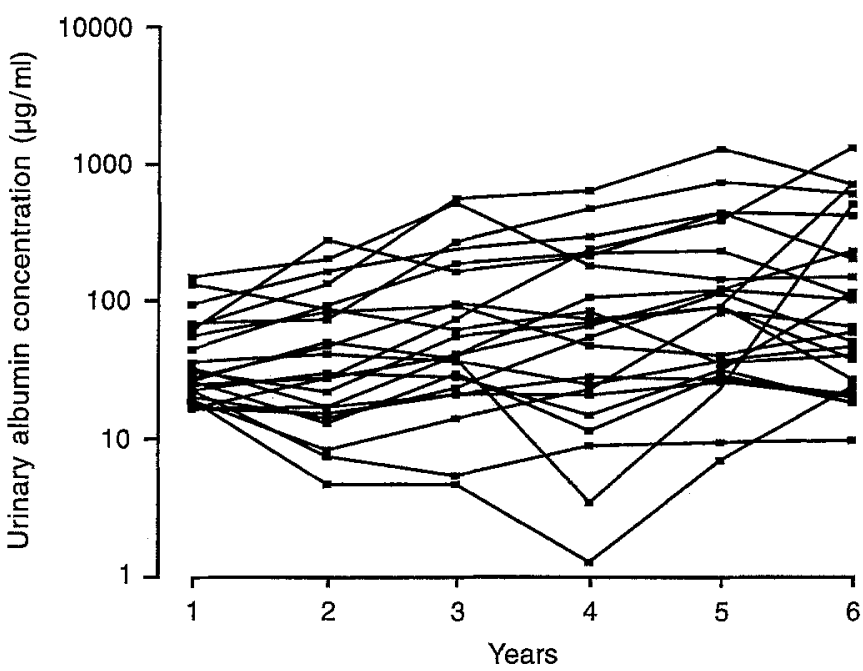

Fig.3. Individual average annual albumin excretion in $24 \mathrm{pa}-$ tients with microalbuminuria during 6 years. On average UAC was increased from $36.4 \mu \mathrm{g} / \mathrm{ml} \times / \div 1.9$ to $96.9 \times / \div 4.0$, $p<0.01$

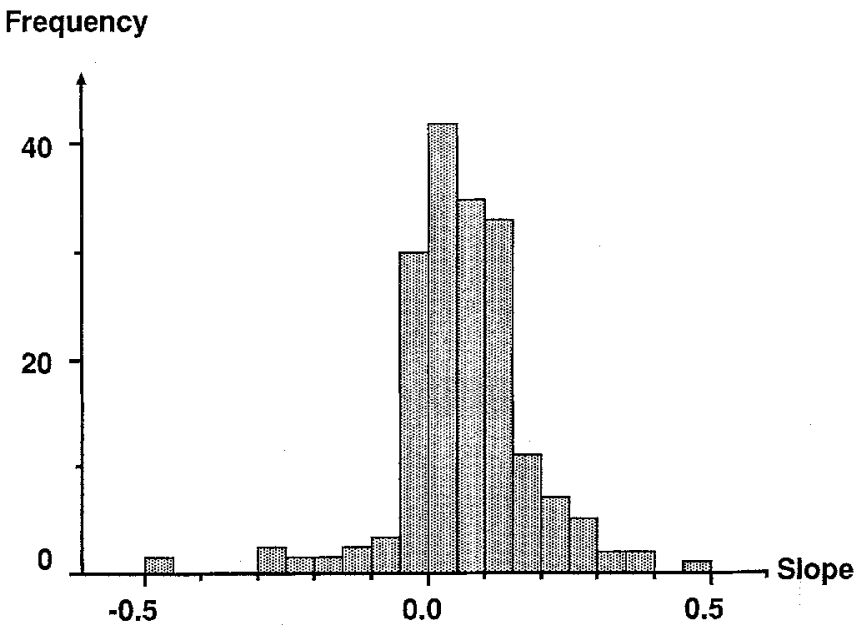

Fig.4. Distribution of slope among patients with at least 4 years' follow-up. The overall increase was significantly different from zero $p<0.0001$

all 6 years $(n=135)$, at least 4 years $(n=178)$, and more than 2 years $(n=237)$. The regression coefficients were $0.0694,0.0697$ and 0.0739 , respectively, corresponding to annual increases in albuminuria of $17 \%, 17 \%$ and $19 \%$. There was a rather large interindividual variation as demonstrated in Figure 4, which displays the distribution of slope among patients with at least 4 years' follow-up. Though tending to be slightly greater, the rate of increase in albuminuria did not significantly differ between patients with normal albumin excretion $(16.4 \%)$ and microalbuminuria $(23.3 \%)$ (in those with at least four years' follow-up figures were $17.2 \%$ and $24.5 \%$ respectively).

Which factors influence or associate with the rate of increase? Associations between clinical variables and the relative rate of increase appear in Table 4 for pa-
A. Schmitz et al.: Systolic BP relates to progression of albuminuria

Table 4. Correlations between quantitative variables and albuminuria at baseline, average albuminuria and slope in patients with complete 6 year follow-up. Significant associations $(p<0.05)$ are indicated by bold figures

\begin{tabular}{llllr}
\hline & & $\begin{array}{l}\text { Baseline } \\
\text { albuminuria }\end{array}$ & Average & Slope \\
\hline Age & (B) & 0.009 & 0.004 & $\mathbf{0 . 1 8 9}$ \\
Body mass index & (S) & 0.077 & 0.050 & -0.164 \\
Plasma glucose & (B) & 0.131 & 0.129 & -0.083 \\
& (S) & 0.088 & 0.128 & -0.007 \\
& (A) & 0.115 & 0.166 & 0.056 \\
HbA $_{1 C}$ & (S) & $\mathbf{0 . 2 2 4}$ & $\mathbf{0 . 2 6 3}$ & 0.071 \\
Blood pressure $_{\quad}$ systolic & (S) & 0.127 & $\mathbf{0 . 2 2 1}$ & $\mathbf{0 . 2 5 8}$ \\
$\quad$ diastolic & (S) & 0.072 & 0.140 & 0.136 \\
Baseline albuminuria & & 1 & 0.890 & -0.050 \\
Average & (S) & 0.890 & 1 & $\mathbf{0 . 3 0 5}$ \\
\hline
\end{tabular}

Table 5. Multiple regression analyses in patients with at least 4 years and (complete) 6 years of follow-up, with slope as dependent variable

\begin{tabular}{lllllll}
\hline Variable & \multicolumn{2}{l}{ At least 4 years } & & \multicolumn{2}{l}{6 years } \\
\cline { 2 - 3 } & reg. coeff. & $p$-value & & reg. coeff. & $p$-value \\
\hline $\begin{array}{lllllll}\text { Systolic blood } \\
\text { pressure }\end{array}$ & 0.00147 & 0.0012 & & 0.00102 & 0.0090 \\
Average UAC & 0.0323 & 0.018 & & 0.0421 & 0.0013 \\
Sex & - & 0.18 & & - & 0.92 \\
Age & - & 0.78 & & - & 0.19 \\
Body mass & & & & & \\
index & - & 0.09 & & -0.0048 & 0.015 \\
$R^{2}$ & $\mathbf{0 . 1 1 5}$ & & & $\mathbf{0 . 1 7 4}$ & \\
\hline
\end{tabular}

reg. coeff.: regression coefficient

tients with complete 6-year follow-up. Slope was significantly associated with age, systolic blood pressure and average albuminuria. For patients with at least 4 years of follow-up, slope correlated with systolic $(r=0.291)$ and diastolic blood pressure $(r=0.226)$ and average $(r=0.237)$. Multiple regression analyses, Table 5, showed that systolic blood pressure and average UAC were the only variables remaining with a significant influence on slope in both categories. As it appears, the percentage of the variation explained by these variables $\left(R^{2}\right)$ was modest.

Concerning antihypertensive medication, patients receiving this therapy and higher blood pressure $(164 / 89 \mathrm{~mm} \mathrm{Hg}$ vs $155 / 85, p<0.01$, but the relationship between blood pressure and slope was independent of whether or not the patients were medicated. Also, number of years of follow-up or mode of antidiabetic treatment were without any significant influence.

Among patients followed for at least 4 years, 46 progressed, Table 6 . The average slope was $48 \%$. Progressors had higher systolic blood pressure 
Table 6. Number and percent of patients characterised as progressors in the group with at least 4 years of follow-up

\begin{tabular}{llcc}
\hline & \multicolumn{3}{c}{ Albuminuria } \\
\cline { 3 - 4 } & & Baseline & \multicolumn{1}{c}{ End } \\
\hline $\mathrm{N} \rightarrow \mathrm{M}$ & $n=34 \approx 25 \%$ & $7.3 \times / \div 1.8$ & $28.4 \times / \div 1.9$ \\
$\mathrm{M} \rightarrow \mathrm{P}$ & $n=11 \approx 32 \%$ & $47.3 \times / \div 2.0$ & $499.0 \times / \div 1.9$ \\
$\mathrm{~N} \rightarrow \mathrm{P}$ & $n=1$ & 3.0 & 1051.9 \\
$\mathrm{M} \rightarrow \mathrm{N}$ & $n=3 \approx 9 \%$ & 30.9 & 12.3 \\
$\mathrm{P} \rightarrow \mathrm{M}$ & $n=1$ & 446.4 & 87.0 \\
$\mathrm{P} \rightarrow \mathrm{N}$ & $n=1$ & 505.6 & 16.7 \\
\hline
\end{tabular}

Last three rows include the five regressing patients. Albuminuria is given at baseline and at end of follow-up. N, Normal albumin excretion; M, microalbuminuria; $\mathrm{P}$, proteinuria. Average UAC $\mu \mathrm{g} / \mathrm{ml}$

$(165 \mathrm{mmHg} \pm 20$ vs $156 \pm 17), p<0.01$, and poorer glycaemic control $\left(\mathrm{HbA}_{1 \mathrm{c}}: 8.2 \% \pm 1.5\right.$ vs $\left.7.7 \pm 1.3\right)$, $p<0.05$, as compared to their non-progressing counterparts. They were similar in age $(65.0$ years $\pm 5.0 \mathrm{vs}$ $63.4 \pm 5.4)$ and diastolic blood pressure $(89 \mathrm{~mm} \mathrm{Hg} \pm$ 8 vs $86 \pm 9$ ) was not significantly different. Albuminuria at baseline was elevated: $11.2 \mu \mathrm{g} / \mathrm{ml} \times / \div 2.7$ (range $1.2-140$ ) vs $5.6 \times 1 \div 2.9(1-149), p<0.001$. Those with normal albumin excretion had values of $7.1 \mu \mathrm{g} / \mathrm{ml} \times 1 \div 1.8$ vs $3.8 \times 1 \div 1.9, p<0.0001$, but the ranges were similar $1.2-14.9 \mu \mathrm{g} / \mathrm{ml}$ and $1-14.5 \mu \mathrm{g} / \mathrm{ml}$. A total of five patients regressed; three from microalbuminuria to normal UAC, and two with proteinuria to microalbuminuria and normal albumin excretion, respectively.

A total of 80 patients died: $24 \%$ of those with normal albumin excretion, $35 \%$ of microalbuminuric patients and $60 \%$ of patients with proteinuria. Those who died were older (65.7 years \pm 4.2 vs $63.3 \pm 5.4$ $p<0.001$ ) and had a higher albumin excretion both at baseline $16.8 \mu \mathrm{g} / \mathrm{ml} \times / \div 6.4$ vs $7.6 \times 1 \div 3.9$ $(p<0.001)$ and on average $(p<0.01)$, as compared to the remainder. The slope was, however, not significantly different among those who died $(20.6 \%)$ or survived $(17.6 \%)$.

The patients who did not complete the study were, apart from being slightly younger, no different with regard to any of the clinical parameters, as compared to the remainder: age: 62.6 years \pm 5.4 vs $64.4 \pm 5.1$, $p<0.05$; duration of diabetes: 8.4 years \pm 6.2 vs $7.7 \pm 5.9$, BMI: $29.3 \mathrm{~kg} / \mathrm{m}^{2} \pm 7.2$ vs $28.3 \pm 4.6$; plasma glucose at baseline: $9.1 \mathrm{mmol} / 1 \pm 2.3$ vs $9.3 \pm 2.4$; study period: $9.6 \mathrm{mmol} / 1 \pm 2.1$ vs $9.6 \pm 2.3$; all: $8.9 \mathrm{mmol} / 1 \pm 2.1$ vs $9.0 \pm 1.8 ; \mathrm{HbA}_{1 \mathrm{C}}: 7.7 \% \pm 1.8$ vs $7.9 \pm 1.2$; systolic blood pressure: $154 \mathrm{~mm} \mathrm{Hg} \pm 18$ vs $158 \pm 21$; diastolic blood pressure: $86 \mathrm{~mm} \mathrm{Hg} \pm 10$ vs $87 \pm 10$; urinary albumin 85 : $9.6 \mu \mathrm{g} / \mathrm{ml} \times / \div 4.9$ vs $9.6 \times / \div 4.8$.

\section{Discussion}

In the present study, the average relative rate of increase of albuminuria amounted to $17 \%$ per year and our results point to two variables with positive association to this increase: systolic blood pressure and level of albuminuria.

Slope generally showed a marked interindividual variation, only a modest percentage of which could be explained by the variables analysed. Albumin excretion was assessed by concentrations in first morning urine samples, rather than in standardised timed collections, but the former is a valid estimate of UAE. Increased early morning UAC predicts raised UAE with a sensitivity of approximately $90 \%$ and is well correlated to UAE [24-26]. A former longitudinal study demonstrated a conspicuous intraindividual variability during the evolution of albuminuria [27], and the day-to-day variation is known to amount up to $40-50 \%$ [28]. In the present study, slope was estimated from yearly average based on several measurements. The population of NIDDM patients is probably a mosaic of those who eventually do develop complications and those who do not, as is the case in IDDM. In a former study we observed that a substantial number of similar patients remained normoalbuminuric over $10-13$ years [6]. Among present participants 46 were defined as progressors, corresponding to $27 \%$ of the eligible population (172 non-proteinuric patients with at least 4 years of follow-up). Progressors were characterised by elevated systolic blood pressure, higher level of albuminuria and poorer glycaemic control. Even though average baseline albuminuria was also increased among normoalbuminuric progressors, the lowest value was $1.2 \mu \mathrm{g} / \mathrm{ml}$; serial measurements thus being mandatory for identifying such patients.

The results concerning evolution in albuminuria are difficult to compare to previous studies, which have been based mainly on two-point analyses in both types of diabetes. The annual increase in albuminuria in IDDM patients with incipient nephropathy followed for 5 years was $18 \%$ [29], and in 13 patients characterised by progression from normo- to microalbuminuria $38 \%$ per year during 914 years [30]. Even less data are available in NIDDM. A 10-year follow-up study [31] demonstrated that $20 \%$ of patients with microalbuminuria will develop proteinuria over a decade, and nine NIDDM patients progressing as above showed a rate of increase of $42 \%$ per year [30]. Cooper et al. [32] followed 61 NIDDM patients, 12 of whom were identified as progressing over a mean of 7 years. In contrast to the present finding there were no statistically significant differences in either blood pressure or glycaemic control between groups. This may be due to the smaller size of that population. 
The higher rate of progression among patients with higher albumin excretion but no significant difference in slope among the albuminuria groups may seem to be contradictory. The division of patients in three groups is, however, arbitrary and based upon measurements at baseline; the latter will thus be subject to "regression towards the mean" effects. Average and slope are independent within patients and therefore uninfluenced by this phenomenon.

The longitudinal study of elderly people with NIDDM is inevitably compromised by the high frequency of disability and mortality and the selective influence of risk factors, among them elevated albuminuria. Also in our study a substantial number of patients died $(29 \%)$ or were unable or unwilling to continue $(22 \%)$. This leaves the 6-year cohort as a selected population. Overall, however, the results in the three subgroups were similar, though the patients with few years of follow-up did not add to the prospective results, apart from introducing more variation.

Glycaemic control has been shown to be important with regard to the development of diabetic microvascular complications [33-38], whereas its influence on macrovascular disabilities so far is doubtful [39-42]. As in previous studies glycaemic control was poorer in those with elevated albuminuria [1], but was without influence on slope. Gilbert et al. [30] reported a significant association between rate of change in $\mathrm{UAE}$ and $\mathrm{HbA}_{1 \mathrm{C}}$ in progressors, but whether this was due to those with poor control having a higher average is unclear. Optimising glycaemic control reduces albuminuria at least in shortterm studies $[12,15-16]$, but the long-term consequences of such intervention are unknown in NIDDM patients.

In NIDDM the relation between systolic blood pressure and progression of albuminuria in our view is noticeable. In IDDM both systolic and diastolic blood pressure are associated with albuminuria, and with development of incipient and overt nephropathy blood pressures rise steadily [3, 29, 43, 44]. Antihypertensive therapy reduces albuminuria and retards the decline in kidney function [3, 29, 43-47]. Earlier we demonstrated that systolic blood pressure was related to the moderate rate of decline in kidney function in NIDDM patients with normo- or microalbuminuria [48]. A similar finding was reported by Gall et al. [49] in patients with proteinuria. In NIDDM several cross-sectional studies reveal that systolic blood pressure relates to albuminuria, whereas the connection with diastolic pressure is modest $[1$, $6-8,13,50-52]$. Systolic blood pressure (also isolated systolic hypertension) appears to be the predominant associate with cardiovascular disease $[1,51,53]$. Albuminuria in NIDDM may reflect general vascular disease rather than merely diabetic glomerulopathy $[1,54]$.
In agreement with the consistent inference in previous studies, those patients who died had shown enhanced albumin excretion. The main causes of death are known to relate to cardiovascular disease. The relationship between increased albuminuria and a poor prognosis is yet not understood, and has not been explained by any known risk factors either alone or in combination. There are several studies to indicate that antihypertensive therapy may be beneficial as albuminuria is reduced [55-57] and possibly renal function can be preserved and possibly renal function can be preserved in NIDDM [58] as it is in IDDM.

The present study also points to blood pressure, besides albuminuria, as candidates for intervention. However, the interindividual variation in rate of progression of albuminuria is far from being explained by these factors alone. Whether therapy directed against them will improve survival or renal and cardiovascular morbidity is sofar unknown, necessitating long-term studies. Furthermore other explaining factors are desired.

Acknowledgements. The skilful technical assistance of Ms. E. Bang Hansen, Ms. J. Hansen and Ms. M. Møller is greatly appreciated.

\section{References}

1. Schmitz A (1992) The kidney in non-insulin-dependent diabetes. Studies on glomerular structure and function and the relationship between microalbuminuria and mortality. Acta Diabetol 29: 47-69

2. Mogensen CE, Damsgaard EM, Frøland A, Nielsen S, de Fine Olivarius N, Schmitz A (1992) Microalbuminuria in non-insulin-dependent diabetes. Clin Nephrol 38: s28-s38

3. Mogensen CE, Schmitz O (1988) The diabetic kidney: from hyperfiltration and microalbuminuria to end-stage renal failure. Med Clin North America 72: 1465-1492

4. Fabre J, Balant LP, Dayer PG, Fox HM, Vernet AT (1982) The kidney in maturity onset diabetes mellitus: a clinical study of 510 patients. Kidney Int 21: 730-738

5. Tung P, Levin SR (1988) Nephropathy in non-insulin-dependent diabetes mellitus. Am J Med 85 [suppl 5 A]: 131136

6. Schmitz A, Væth M (1988) Microalbuminuria: a major risk factor in non-insulin-dependent diabetes. A 10-year followup study of 503 patients. Diabet Med 5: 126-134

7. Neil A, Hawkins M, Potok M, Thorogood M, Cohen D, Mann J (1993) A prospective population-based study of microalbuminuria as a predictor of mortality in NIDDM. Diabetes Care 16: 996-1003

8. Gall M-A, Rossing P, Sk $\varnothing t t$ P et al. (1991) Prevalence of micro- and macroalbuminuria, arterial hypertension, retinopathy and large vessel disease in European type 2 (non-insulin-dependent) diabetic patients. Diabetologia 34: 655-661

9. Marshall SM, Alberti KGMM (1989) Comparison of the prevalence and associated features of abnormal albumin excretion in insulin-dependent and non-insulin-dependent diabetes. Q J Med 70: 61-71

10. Damsgaard EM (1988) Prevalence and incidence of microalbuminuria in non-insulin-dependent diabetes: relations to other vascular lesions. In: Mogensen CE (ed) The kid- 
ney and hypertension in diabetes mellitus. Martinus Nijhoff Publishing, Boston pp 59-63

11. Ballard DJ, Humphrey LL, Melton LJ III et al. (1988) Epidemiology of persistent proteinuria in type II diabetes mellitus. Population-based study in Rochester, Minnesota. Diabetes 37: 405-412

12. Schmitz A, Hvid Hansen H, Christensen T (1989) Kidney function in newly diagnosed type 2 (non-insulin-dependent) diabetic patients, before and during treatment. Diabetologia 32: 434-439

13. Olivarius N de F, Andreasen AH, Keiding N, Mogensen CE (1993) Epidemiology of renal involvement in newly-diagnosed middle-aged and elderly diabetic patients. Crosssectional data from the population-based study "Diabetes Care in General Practice", Denmark. Diabetologia 36: 1007-1016

14. Standl E, Stiegler H (1993) Microalbuminuria in a random cohort of recently diagnosed type 2 (non-insulin-dependent) diabetic patients living in the Greater Munich Area. Diabetologia 36: 1017-1020

15. Martin P, Hampton KK, Walton C, Tindall H, Davies JA (1990) Microproteinuria in type 2 diabetes mellitus from diagnosis. Diabet Med 7: 315-318

16. Patrick AW, Leslie PJ, Clarke BF, Frier BM (1990) The natural history and associations of microalbuminuria in type 2 diabetes during the first year after diagnosis. Diabet Med 7: 902-908

17. Mogensen CE (1987) Microalbuminuria as a predictor of clinical diabetic nephropathy. Kidney Int 31: 673-689

18. Humphrey LL, Ballard DJ, Frohnert PP, Chu C-P, O'Fallon WM, Palumbo PJ (1989) Chronic renal failure in non-insulin-dependent diabetes mellitus. A population-based study in Rochester, Minnesota. Ann Intern Med 111: 788-796

19. Schmitz A (1993) Renal function changes in middle-aged and elderly Caucasian type 2 (non-insulin-dependent) diabetic patients - a review. Diabetologia 36: 985-992

20. Damsgaard EM, Frøland A, Jørgensen OD, Mogensen CE (1992) Eight-to nine-year mortality in known non-insulin dependent diabetics and controls. Kidney Int 41: 731-735

21. Mattock MB, Morrish NJ, Viberti GC, Keen H, Fitzgerald AP, Jackson G (1992) Prospective study of microalbuminuria as predictor of mortality in NIDDM. Diabetes 41: 736-741

22. Christensen CK, Ørskov C (1984) Rapid screening PEG radioimmunoassay for quantification of pathological microalbuminuria. Diabetic Nephropathy 3: 92-94

23. Ellis G, Diamandis EP, Giesbrecht EE, Daneman D, Allen LC (1984) An automated "high-pressure" liquid-chromatographic assay for haemoglobin $A_{1 C}$. Clin Chem 30 : 1746-1752

24. Gatling W, Knight C, Hill RD (1985) Screening for early diabetic nephropathy: which sample to detect microalbuminuria? Diabet Med 2: 451-455

25. Hutchinson AS, O'Reilly DStJ, MacCuish AC (1988) Albumin excretion rate, albumin concentration, and albumin/ creatinine ratio compared for screening diabetics for slight albuminuria. Clin Chem 34: 2019-2021

26. Eshøj O, Feldt-Rasmussen B, Larsen ML, Mogensen EF (1987) Comparison of overnight, morning and 24-hour urine collections in the assessment of diabetic microalbuminuria. Diabet Med 4: 531-533

27. Jerums G, Cooper ME, Seeman E, Murray RML, McNeil JJ (1987) Spectrum of proteinuria in type I and type II diabetes. Diabetes Care 10: 419-427

28. Feldt-Rasmussen B, Mathiesen ER (1984) Variability of urinary albumin excretion in incipient diabetic nephropathy. Diabetic Nephropathy 3: 101-103
29. Christensen CK (1991) The pre-proteinuric phase of diabetic nephropathy. Dan Med Bull 38: 145-160

30. Gilbert RE, Tsalamandris C, Bach LA et al. (1993) Longterm glycemic control and the rate of progression of early diabetic kidney disease. Kidney Int 44: 855-859

31. Mogensen CE (1984) Microalbuminuria predicts clinical proteinuria and early mortality in maturity-onset diabetes. N Eng1 J Med 310: 356-360

32. Cooper ME, Frauman A, O'Brien RC, Seeman E, Murray RML, Jerums G (1988) Progression of proteinuria in type 1 and type 2 diabetes. Diabet Med 5: 361-368

33. Pirart J (1978) Diabetes mellitus and its degenerative complications: a prospective study of 4,400 patients observed between 1947 and 1973. Diabetes Care 1: 168-188

34. Pirart J (1978) Diabetes mellitus and its degenerative complications: a prospective study of 4,400 patients observed between 1947 and 1973. Diabetes Care 1: 252263

35. The Diabetes Control and Complications Trial Research Group (1993) The effect of intensive treatment of diabetes on the development and progression of long-term complications in insulin-dependent diabetes mellitus. N Engl J Med 329: 977-986

36. Wang PH, Lau J, Chalmers TC (1993) Meta-analysis of effects of intensive blood-glucose control on late complications of type 1 diabetes. Lancet 341: 1306-1309

37. Feldt-Rasmussen B, Mathiesen ER, Deckert T (1986) Effect of two years of strict metabolic control on progression of incipient nephropathy in insulin-dependent diabetes. Lancet ii: $1300-1304$

38. Bangstad H-J (1994) Early diabetic nephropathy. The relationship between blood glucose control and kidney function and morphology in insulin-dependent diabetes mellitus (thesis). Oslo, Department of Paediatrics, Aker Diabetes Research Centre, Aker University Hospital, Oslo University

39. Borch-Johnsen K, Kreiner S (1987) Proteinuria - value as predictor of cardiovascular mortality in insulin-dependent diabetes mellitus. BMJ 294: 1651-1654

40. Jarrett RJ (1984) Type 2 (non-insulin-dependent) diabetes mellitus and coronary heart disease - chicken, egg or neither? Diabetologia 26: 99-102

41. Haffner SM, Stern MP, Hazuda HP, Mitchell BD, Patterson JK (1990) Cardiovascular risk factors in confirmed prediabetic individuals. Does the clock for coronary heart disease start ticking before the onset of clinical diabetes? JAMA 263: 2893-2898

42. Knatterud GL, Klimt CR, Levin ME, Jacobson ME, Goldner MG (1978) Effects of hypoglycaemic agents on vascular complications in patients with adult-onset diabetes. VII. Mortality and selected nonfatal events with insulin treatment. JAMA 240: 37-42

43. Parving $\mathrm{H}-\mathrm{H}$, Andersen AR, Smidt UM, Hommel E, Mathiesen ER, Svendsen PA (1987) Effect of antihypertensive treatment on kidney function in diabetic nephropathy. BMJ 294: 1443-1447

44. Viberti GC, Mogensen CE, Groop L, Pauls JF for the European Microalbuminuria Captopril Study Group (1994) Effect of captopril on progression to clinical proteinuria in patients with insulin-dependent diabetes mellitus and microalbuminuria. JAMA 271:275-279

45. Marre M, Chatellier G, Leblanc H, Guyenne T-T, Ménard $\mathrm{J}$, Passa $\mathrm{Ph}$ (1988) Prevention of diabetic nephropathy with enalapril in normotensive diabetics with microalbuminuria. BMJ 297: 1092-1095

46. Mathiesen ER, Hommel E, Giese J, Parving H-H (1991) Efficacy of captopril in postponing nephropathy in normo- 
tensive insulin-dependent diabetic patients with microalbuminuria. BMJ 303: 81-87

47. Björck S, Mulec H, Johnsen SA, Nordén G, Aurell M (1992) Renal protective effect of enalapril in diabetic nephropathy. BMJ 304: 339-343

48. Nielsen S, Schmitz A, Rehling A, Mogensen CE (1993) Systolic blood pressure relates to the rate of decline of glomerular filtration rate in type II diabetes. Diabetes Care 16: 1427-1432

49. Gall M-A, Nielsen FS, Smidt UM, Parving H-H (1993) The course of kidney function in type 2 (non-insulin-dependent) diabetic patients with diabetic nephropathy. Diabetologia 36: 1071-1078

50. Keen H, Chlouverakis C, Fuller J, Jarrett RJ (1969) The concomitants of raised blood sugar: studies in newly-detected hyperglycaemics. II. Urinary albumin excretion, blood pressure and their relation to blood sugar levels. Guys Hosp Rep 118: 247-254

51. Standl E, Stiegler H, Janka HU, Mehnert H (1988) Risk profile of macrovascular disease in diabetes mellitus. Diabete Metab (Paris) 14: 505-511

52. Schmitz A, Mau Pedersen M, Hansen KW (1991) Blood pressure by $24 \mathrm{~h}$ ambulatory recordings in type 2 (non-insulin dependent) diabetics. Relationship to urinary albumin excretion. Diabete Metab (Paris) 17: 301-307
53. Ibsen H, Hilden T (1990) New views on the relationship between coronary heart disease and hypertension. J Intern Med 227: 77-79

54. Deckert T, Feldt-Rasmussen B, Borch-Johnsen K, Jensen T, Kofoed-Enevoldsen A (1989) Albuminuria reflects widespread vascular damage: the steno hypothesis. Diabetologia 32: 219-226

55. Melbourne Diabetic Nephropathy Study Group (1991) Comparison between perindopril and nifedipine in hypertensive and normotensive diabetic patients with microalbuminuria. BMJ 302: 210-216

56. Chan JCN, Cockram CS, Nicholls MG, Cheung CK, Swaminathan R (1992) Comparison of enalapril and nifedipine in treating non-insulin dependent diabetes associated with hypertension: one-year analysis. BMJ 305: 981-985

57. Lacourcière Y, Nadeau A, Poirier L, Tancréde G (1993) Captopril or conventional therapy in hypertensive type II diabetics. Three-year analysis. Hypertension 21: 786-794

58. Ravid M, Savin H, Jutrin I, Bental T, Katz B, Lishner M (1993) Long-term stabilizing effect of angiotensin-converting enzyme inhibition on plasma creatinine and on proteinuria in normotensive type II diabetic patients. Ann Intern Med 118: 577-581 